\title{
Charlie Hebdo as a critical event in a secondary school: Muslim students' complex positioning in relation to the attack
}

Transcultural Psychiatry $0(0) 1-13$

(C) The Author(s) 2020 Article reuse guidelines: sagepub.com/journals-permissions DOI: 10.1 | 177/I36346/5209038|4 journals.sagepub.com/home/tps

SAGE

\author{
Carola Tize', Lidewyde Berckmoes ${ }^{2}$, Joop de Jong ${ }^{3,4,5}$ and \\ Ria Reis ${ }^{1,6,7,8}$
}

\begin{abstract}
This paper examines responses to the 2015 terror attack on Charlie Hebdo, a French satirical magazine, amongst students in a secondary school in Berlin-Neukölln, Germany. The Charlie Hebdo attack occurred in the final weeks of a 19-month ethnographic study in the community. By analyzing the responses in the school to this critical event, we identify what is at stake for Muslim students. Students presented many explanations for why the attack happened, and opinions on whether the attackers' actions were justified. Staff were alarmed about students' viewpoints that they considered "extreme". These dynamics resulted in conflicts and misunderstandings amongst students, and between students and staff. Yet, we show that, rather than the violence itself, or questions about its legitimacy, it was everyday processes in students' lives - e.g., bullying, peer pressure and discrimination, and feelings of being misrepresented and misunderstood - that were central to students' reactions to the event. We suggest that to understand students' reactions, both the immediate and the broader socio-political contexts must be considered, particularly rising xenophobia and processes of polarization in Germany and Europe at large. We thus conclude that to understand young people's reactions to terrorist acts, we need to look beyond initial statements and explore ethnographically how wider contexts shape the actions, reactions, and future orientations of young Muslims in Europe.
\end{abstract}

\section{Keywords}

Charlie Hebdo, critical event, Germany, processes of polarization, school, terrorism

\section{Introduction}

On January 7, 2015, two brothers, Saïd and Chérif Kouachi, forced themselves into the Paris offices of the satirical magazine Charlie Hebdo, killing 12 and injuring 11 others. The Kouachis claimed that their actions were a retaliation against a satirical depiction of the prophet Mohammad published in the magazine. The brothers claimed affiliation with Al Qaeda's Yemen branch, which took responsibility for the attack. Following the attack, a two-day manhunt ensued, resulting in additional casualties, including five occupants of a Jewish supermarket that were held hostage and eventually killed by an accomplice.

The effects were global. On January 11, 40 world leaders met in Paris in a walk against terrorism, alongside approximately 3.7 million people across France and many more worldwide. The catchphrase "Je suis
Charlie" ("I am Charlie"), not necessarily an expression of affiliation to the magazine, was adopted to symbolize the importance of free speech, secularism, and

\footnotetext{
'Amsterdam Institute for Social Science Research, University of Amsterdam, Amsterdam, the Netherlands

${ }^{2}$ African Studies Centre Leiden, Leiden University, Leiden, the Netherlands

${ }^{3}$ University Medical Center, Amsterdam, Amsterdam, the Netherlands

${ }^{4}$ Boston University School of Medicine, Boston, MA, USA

${ }^{5}$ Rhodes University, Grahamstown, South Africa

${ }^{6}$ Leiden University Medical Centre, Leiden, Netherlands

${ }^{7}$ Amsterdam Institute of Global Health and Development, Amsterdam, the Netherlands

${ }^{8}$ Children's Institute, University of Cape Town, Cape Town, South Africa
}

\section{Corresponding author:}

Carola Tize, AISSR/University of Amsterdam, Postbus 15718, I00I NE Amsterdam.

Email: c.p.tize@uva.nl 
democracy (Fassin, 2015). In France and beyond, the attack on Charlie Hebdo came to represent evil - an enemy that needed to be eliminated (Bertelsen \& Zagato, 2015). The attack was described by the media as "the French 9/11"; for some, they came to symbolize the "other" who seemingly threatened European and Western identity (Lichtfield, 2015).

For many of Europe's Muslims, the attack brought to the forefront longstanding feelings of misrepresentation and discontent. Je suis Charlie and anti-Islam movements across Europe inspired counter-reactions, such as the slogan "Je ne suis pas Charlie" ("I am not Charlie"), causing political and social outrage against migrants, who were perceived as unwilling to integrate. As Fassin (2015) points out in his analysis of Charlie Hebdo, a highly diverse group of Muslims, as well as people of other faiths who felt attacked by humiliating depictions of the prophet in a satirical magazine, were forced to either identify with that same magazine through Je suis Charlie or to be identified as antiintegration. Simply renouncing violence and terrorism was not enough.

The attack on Charlie Hebdo occurred during the final weeks of the first author's (CT) ethnographic research in a secondary school in Berlin-Neukölln, Germany. ${ }^{1}$ The reactions of students to the attack attracted media attention and the principal turned away media efforts to visit the school and interview students (c.f. Wiegel, 2015). Despite recent trends of gentrification by affluent students and young families, Berlin-Neukölln has a longstanding reputation for being an Ausländerbezirk (foreigner district), characterized by poverty and social problems (e.g., violence and criminal families). While the population shift caused by gentrification is visible on the streets, $90 \%$ of the local secondary school's student population consists of children of migrants from refugee, low income, and welfare families.

The school where the first author (CT) conducted fieldwork research has a multi-ethnic population, in which most students identify as Muslims. Many of these Muslim students are the children of refugees who arrived in the 1980s, 90s, and early 2000s from the Middle East, with a majority from Lebanon escaping the civil war and the dismal conditions of the Palestinian refugee camps. Others are descendants of Turkish guest workers who came to Germany in order to fill in the gaps caused by the labor shortages that followed the second world war. They are a diverse population and vary greatly in cultural and ethnicreligious traditions. ${ }^{2}$

In this paper, we explore and analyze students' reactions to the Charlie Hebdo attack and examine how the events unfolded in a secondary school in Berlin-Neukölln. We thereby approach the attack and reactions to it as a "critical event", constituted by and constitutive of social processes. In this sense, we draw on Gluckman's foundational approach to documenting and analyzing events as a "social situation". Gluckman argued that this approach could be used to identify wider societal structures and social shifts resulting from the situation of interest (Gluckman, 1940; Kapferer, 2010). The focus is on atypical situations which, through conflict and crisis, illuminate patterns and ways of being in relation to the social and political tensions that influence everyday life and feelings of inclusion and exclusion. We look at students' and teachers' reactions to Charlie Hebdo to illuminate the social and political tensions already at play in the lives of students in Berlin-Neukölln, as well as to examine how these tensions gain new impetus as a consequence of the Charlie Hebdo event. We suggest that understanding what is at stake for students during critical times of social and political turmoil demands a broader perspective that takes into account the wider societal structures and processes surrounding the event. In other words, by asking what is at stake for these students, we can show how everyday processes in their lives, such as bullying and peer pressure, as well as feelings of discrimination, misrepresentation, and being misunderstood, were central to their reactions to Charlie Hebdo. Through these investigations, we have developed greater insight into how their reactions, shifting subject positions, and identities provide a window into their insecure positions within the broader socio-political processes already in play. We found that for these students, at stake are their struggles to situate their identities and establish a sense of belonging amidst longstanding and rising xenophobia and polarization. We thus argue that ethnographic approaches are a valuable method of contextualizing young people's reactions to terrorist acts and may help to prevent further polarization of discourses and populations.

\section{Methods}

This ethnographic research was conducted by the first author (CT) in the district of Berlin-Neukölln over 19 months between 2013 and 2015. It employed participant observation methods in schools, neighborhoods, families, and local events. The ethnographic data collection included over 90 recorded interviews, in addition to informal conversations with students, teachers, families, social workers, and others involved in child and family well-being. The data presented here is from research in an elementary school and an integrated secondary school. The first year of research in the elementary school focused on grades 4-6 (ages 8-13), after which the focus shifted to grades $7-8$ in the secondary school (ages $12-15){ }^{3}$ With this transition, some students were followed to the secondary 
school, tracing their trajectories over the entire 19 months. While the research in the elementary school provided insights into the perceptions and the environment of the students prior to Charlie Hebdo, the data in this article and the featured post-Charlie Hebdo reactions are from the secondary school.

Home visits with an intercultural mediator (who also translated) allowed us to interview mothers, and occasionally both parents as well as siblings. The research with parents had a strong focus on mothers because they were more accessible and open to the first author, who is also a woman. ${ }^{4}$ Although interviews with fathers were possible outside of a family setting, the choice to not interview them fostered trust within the circles of the mothers. The first author also participated in and observed weekly parent initiatives, e.g., parent breakfasts, parent-teacher interviews, and intervention and information sessions, as well as meetings and initiatives of a local educational NGO. Finally, a photo project with four students examined spaces they considered safe and unsafe in the district of BerlinNeukölln, and an identity project with a grade 8 class provided insight into factors that shaped young people's foreigner and oppositional identities. All data was entered into the qualitative analysis software NVivo, and was analyzed iteratively and inductively using open and axial coding. As outlined above, we furthermore drew on Gluckman's (1940) extended case method to analyze the structures and processes surrounding Charlie Hebdo as a "critical event". The first author (CT) was given the opportunity to return to the school and receive feedback on the findings of this paper from several students, as well as from the principal and affiliated NGO staff.

In order for students to participate, we adopted the principle of double consent; requiring the parent(s) and the student to give informed consent in order to participate in the research. Pseudonyms were used and any identifying information was omitted to protect the identity of all participants. Research permission was granted by the Amsterdam Institute of Social Science Research (AISSR) Ethics Committee and the AISSR Advisory Board (2013- SSC- 3092), as well as by the Berlin Senate for Education, Youth and Research (signed letter filed).

\section{Migration and polarization in Germany}

The recent refugee crisis of 2015 has painted Germany as a country welcoming of refugees and migrants. However, despite a long history of immigration, there is historical precedent of viewing immigration as unfavorable in Germany, by both government and society (Ellerman, 2009). Additionally, despite the social reality of immigration and settlement, there was little engagement with or recognition of the lives of migrants in Germany until the 1980s (Bock \& McDonald, 2019). This was a result of migrants being viewed by the government and society as temporary, and therefore controllable. The intention was that the guest workers, who began arriving in the 1960s from countries such as Turkey, Greece, Italy, and Spain, would return home after completing their contracts. Likewise, refugees and asylum seekers were grudgingly tolerated, but expected to return to their home countries as soon as possible (Ellerman, 2009). However, policy changes in the 1970s made family unification and long-term residency possible, thereby shifting temporary workers into long-term residents. Germany's continued lack of recognition of its growing migrant population within government and policy left migrants and their children with a 'do-ityourself' integration process (Spielhaus, 2013).

Most guest workers came from Turkey, and representing almost $3.5 \%$ of Germany's population of 82 million, they are Germany's second-largest migrant group. Slightly over half of German residents of Turkish descent were born in Germany (Statistisches Bundesamt, 2017). Despite Muslims representing a mere fraction of Germany's total population, and only a small part of its 12.7 million residents with migrant backgrounds, the shifts in citizenship rights and policies from the 1970s catalyzed fears that Muslim ghettos and parallel societies would develop in urban centers such as Berlin. ${ }^{6}$ For example, in 1973, the German magazine Der Spiegel published an article entitled 'The Turks are coming - run if you can!' (Der Spiegel, 1973). The article casts BerlinKreuzberg, the district adjacent to Neukölln, as an area where "we will drown" (Der Spiegel, 1973, p. 24) if immigration continues. The influx of refugees from Middle Eastern and North African countries in the 1980s and $90 \mathrm{~s}$ added to these fears, as new migrants increasingly gathered in low-income districts, such as BerlinNeukölln. These districts were then viewed as "foreigner" or "Muslim" spaces (Ehrkamp, 2008), full of Turkish and Arabic stores and mosques, and with schools attended sometimes nearly entirely by the children of migrants.

It took until the 2000 change in German citizenship law, which allowed migrants and their children to claim German citizenship, for a large-scale revision of the concept of the German "we" to occur (Bock and McDonald, 2019; Spielhaus, 2013). This shift in citizenship law created a growing public realization that the Südländer (Southern) foreigners were not going to leave. Instead of them becoming recognized as Germans, the focus shifted from seeing them as Ausländer (Foreigners) or 'migrants' to being distinguished as 'Muslims' (Spielhaus, 2006; 2013). The transition to the label 'Muslims' represents a major turn in the last decades within the media, politics, and academia, which have changed the focus of the integration 
debate to religious affiliation, with a prominent focus on Islam. As a result, Muslims became a single-out category and were targeted as a "problem group" associated with welfare use, poverty, and other social problems (Spielhaus, 2006).

Particularly, the media has played a vital part in shaping perceptions of Muslims in Germany. Muslim women have been portrayed as oppressed victims, and Muslim men as oppressors and threats to women (Pratt-Ewing, 2008). ${ }^{7}$ The effects of these portrayals can be seen in political speeches and in the media, as well as in popular discourse, and make it challenging for Muslims to claim cultural citizenship or full sociocultural belonging (Pratt-Ewing, 2008).

The claim "Islam is part of Germany" was made by German president Christian Wulff in 2010 and repeated by Chancellor Angela Merkel in 2015, thereby making public political efforts to include its 4.7 million Muslim residents in German national identity (Stichs, 2016). On both occasions, these statements caused considerable uproar, fueled by polarized media responses. While public recognition and attempts to introduce immigration policy reforms were intended to go beyond the distinction of migrant/native, they in fact caused divisions between holders of nativist ideologies and pluralist concepts of belonging (Foroutan, 2019). Attributions of cultural incompatibility and unsolvable religious differences have long been used against Muslim communities and are increasingly used by growing xenophobic and right-wing movements.

Since migrants and their children have come to claim citizenship and belonging, debates on national identity have become more polarized. Right wing movements, like the Dresden-based nationalistic and anti-Islamic Pegida (in English, 'Patriotic Europeans against the Islamification of the West'), have embraced the view that immigrants, especially Muslims, are destroying Germany through delinquency and anti-European values (Foroutan, 2019). Fears of changing national identity and desires to return to an imagined pre-immigration Germany motivate such movements.

The longstanding exclusion of foreigners from rights of citizenship and naturalization in Germany have impacted how migrants and their children perceive themselves in relation to 'Germans' (Çelik, 2015; Tize \& Reis, 2019). For example, some children of migrants have come to take on 'foreigner' identities, marking their difference with a sense of pride (Tize \& Reis, 2019). Actual and perceived discrimination undoubtedly influence these feelings of being a foreigner. Recent research (SVR, 2018) focusing on discrimination and phenotypical difference in Germany, revealed how experiences of discrimination particularly affect those who are markedly different - e.g., in complexion, dress or accent. The same study found that such experiences were especially prominent amongst Muslims. Despite recent policy and government efforts to include migrants and their children, even today, children and grandchildren of migrants continue to have differential entitlements to belonging.

\section{Charlie Hebdo in the secondary school}

After the attack on Charlie Hebdo, the school was in turmoil. Conflict and uncertainties over how to position themselves arose between students, as well as between students and teachers. While some Muslim students chose to stay silent or openly condoned the violence, others, like those in the interviews below, considered the attack "fake" or "staged". And, in nearly every class from grades 7 to 13 , there were students who sympathized with the terrorists, some vehemently expressing their support to teachers and peers. The following two interview excerpts with students illustrate the confusion, as well as the struggles to situate themselves in relation to the attacks.

CT: Did you follow what happened in Paris?

Naima: Yes. Fake!

Amina: Fake!

CT: What do you mean by fake?

$\mathrm{N}$ : Well, you could see in the videos that it was fake. It's all a lie. They did as if it was terrorists. Islamic terrorists, but that's not true, because where the policeman was lying, they didn't actually shoot at him, instead they shot next to him. They did it as if he was dead, but he wasn't!

A: Now everyone thinks he's dead.

$\mathrm{N}$ : It's all a lie, because Islam says you're not supposed to kill. Nobody is supposed to die because of just something that happened [like the cartoons]. You're supposed to be peaceful and not have terrorists everywhere - I mean Islamists, or whatever.

A: It's all not true.

$\mathrm{N}$ : They're constantly attacking Islam. Islam, Islam, Islam! I don't think it was Muslims who did it.

A: I don't think so either.

$\mathrm{N}$ : The media wants to portray Islam in a bad light.

CT: And that's why you think they staged it?

$\mathrm{N}$ and $\mathrm{A}$ : Yes

CT: What did your parents say?

A: My mom and dad both say its fake.

$\mathrm{N}$ : My brother even saw videos on Facebook where you can see that it was fake...

A: You know what I don't get - they make fun of our prophet and then they wonder why something like that happens! Our prophet is important to us.

(Grade 7 students; both age 13)

CT: Where did you get the information that the attack on Charlie Hebdo wasn't 
real?

Galel: From the internet. And it really didn't happen...

CT: Why do you think people would make something like this up?

G: They are racist against us.

CT: What do you mean with "us"?

G: Against Islam.

Kahlil: Against Islam.

G: Yes, many of them are. Do you know the Pegida groups?

CT: Yes, that's terrible.

G: Charlie Hebdo for me is also racist. They [antiMuslim movements] want something like this. We didn't do it! That's not Islam. Islamic State terror also isn't [Islam]. In Islam you're not allowed to kill. That's a big sin.

K: It also wasn't good what they did in France.

G: A big sin.

(Grade 7 students; ages 12 and 13)

The choice to interview students together allowed peer pressure and considerations of being a 'good Muslim' to surface. In our analyses, the interviews identified four themes that indicated students' positioning in relation to Charlie Hebdo. The first theme, as seen in both interviews above, is that students' responses were quite complex. Insecurity about what to believe, and questions of morality, are evident throughout the excerpts. Both excerpts open with the idea that Charlie Hebdo was faked. However, eventually, the students discuss the sinful status of killing in Islam and reflect on the killers' wrongdoing. They acknowledge that killing is a sin in Islam, highlighting their confusion and uncertainty about how to position themselves. In both interviews, the students contemplate their stances on these issues, but also their positions in relation to each other. One notable element in many of the interviews was how students switched between explanatory stories within the same interview. These changing explanations revealed uncertainty about what the 'correct' story was, and showed sensitivity to their context and the opinions of others, including peers, teachers, and the interviewer.

The second theme, that Charlie Hebdo was staged or faked as the result of a conspiracy, was the most common interpretation amongst the students. The reliance on conspiracy theories to understand a major event such as Charlie Hebdo is not an uncommon or new phenomenon. ${ }^{8}$ Jamil and Rousseau (2011) evaluated how post-9/11 conspiracy theories had strong roots in Pakistani-Canadian immigrant populations, as well as in Pakistan. In France, a public opinion poll showed that $17 \%$ of the population believed there was a conspiracy behind Charlie Hebdo (Golo, 2015). It is significant that the belief in these conspiracy theories in France was particularly high amongst young people and people with low incomes. The interview with Naima and Amina also shows that belief in conspiracy theories was not limited to young people, but also extended to families.

Two predominant conspiracy-theory explanations for the events emerged. One was that the attacks were faked and staged by the Americans, targeting Muslims to make them look bad and ruin the image of European Muslims. Videos circulated amongst the students on platforms such as YouTube, Facebook, and WhatsApp, alleging to show 'proof' that the attacks were faked. A similar theory claimed that the anti-Islamist movements in Europe, such as Pegida, were to blame for faking the attacks. Much like the Americans, the anti-Islamists were seen as targeting Muslims to ruin their reputations and to create a bad image of Islam. Additionally, the media was seen to be aiding anti-Islamists, a culprit in making Islam look bad.

Interestingly, in the school, neither the slogan "I am Charlie" nor "I am not Charlie" were used by the students to situate themselves in relation to the attacks. By claiming that the shootings did not happen as reported in the media, the students were able to avoid taking a clear stance for or against the killers - neither condoning what they did or denying that it was wrong. Students thereby found a third way and avoided feeding into a polarizing discourse on a contentious issue. Through denial, the students were able to repudiate or downplay potential confrontations with staff and other students.

A third theme related to feelings of collective responsibility. Later in the interview, Naima distanced herself from the event by stating: "It's not like my brother did it!" At the same time, many of the students felt personally attacked, both as Muslims and as foreigners in Germany. Galel referred to identifying, and being identified, as a Muslim by stating "they are racist against us" and "we didn't do it!" (emphasis added). Charlie Hebdo thus also evoked feelings and projections of collective responsibility, and caused the students to contemplate questions such as "What Muslim would do this, and why?", "What kind of a Muslim am I?", and "Am I part of this?" This questioning of identity and responsibility contributed to students' wavering and uncertain answers.

The fourth theme concerned the students' feelings of helplessness resulting from being Muslims and not being wanted or heard in Germany. These feelings were revealed particularly clearly in classroom discussions intended by teachers to explore other, more peaceful solutions to the offending depictions of the prophet in Charlie Hebdo. Other possibilities, such as public demonstrations, legal actions, and talks or negotiations were quickly dismissed as ridiculous or without 
effect. For example, during a grade 8 class discussion, Vadim (age 14), a student who supported the violence, yelled into the class discussion: "Talking solves nothing! We've already noticed that. Who listens to talking?! Nobody!" The exclamation had a marked effect on the classroom, and those who argued for more peaceful alternatives were quickly silenced. To Vadim and several others, there was no peaceful way to be heard as a Muslim, or as a foreigner.

The students' exclamations showed that they did not feel heard or supported by the government. German Chancellor Angela Merkel walking in Paris against terrorism with Benjamin Netanyahu and Mahmoud Abbas, the Israeli and Palestinian leaders (along with other global leaders), caused major confusion amongst the students. Netanyahu - whom many of the students saw as being a torturer and murderer - walking against terrorism was perceived as an affront to reality. As Fahim (15) said: "Why was Israel in Paris? They slaughter hundreds of children and then they say they're against violence?" Likewise, Merkel walking with Abbas was similarly confusing. Germany's longstanding support for Israel has, for many of the young people whose refugee history originated in Palestine, long been a sign of not being respected or wanted in Germany.

Looking at the future, interviewees revealed perspectives of pessimism and fear, saying things like "it's all destroyed", "nothing good", and "the world is dirty and will always be that way". While some students viewed the Charlie Hebdo attack as making experiences of discrimination more deeply felt and visible, while not changing their position, others feared that it threatened their futures in Germany and would increase discrimination.

The confusing, controversial, contradictory, and hopeless statements from the students caused turmoil and a sense of helplessness amongst the staff. Many teachers and social workers showed mixed feelings regarding the shifting and controversial reactions of certain students, as can be seen in the following quote by Mrs. Falk, a grade 8 teacher: "I really wasn't too surprised with two of my students [who expressed sympathies to the terrorists] - I almost expected it! But, others? I was truly surprised." Conversations with teachers revealed fear and avoidance of discussing about Charlie Hebdo with their classes, because of their lack of detailed knowledge about Islam, the attack itself, and the threat of having to confront students' counter-narratives and controversial perspectives. As a result, only a few teachers addressed the incident pedagogically, despite the principal's encouragements. Those who did address it did so in their own way, without any training or systematic planning. Teachers like $\mathrm{Mr}$. Herbert, who made an attempt to engage students through alternative news sources, expressed doubt whether they were able to provide new or differing perspectives to their students.

The students' responses to Charlie Hebdo did alert the teachers to the growing, yet previously unsuspected, tensions with which these students were struggling on a daily basis. Suddenly, some teachers sought external help for social interventions, fearing their students' resistance or a risk that they would turn towards extreme viewpoints.

The question we now come to is how to understand and interpret these students' and their teachers' responses. In the following sections, we argue that to understand students' positions and responses to the event, we must understand the socio-political context they are immersed in.

\section{Contextualizing Charlie Hebdo: Religion, positioning, and identities}

In recent years, teachers as well as students have noticed that a strong association and identification with Islam, as a point of differentiation, has taken on an increasingly important role amongst the student body. Prior to the Charlie Hebdo attack, the principal of the school saw the increasing religiousness of many of the students as a temporary phase or trend. Her response and that of her staff was that, as with all other trends, if you do not make a big deal of it, it will pass in due time. Resisting or trying to counteract it will only make it stronger. As a result, the principal's answer to Muslim students wanting a prayer room was just "do it in the hallway and don't disrupt or leave class". For many teachers, however, the shift in the attitudes of students and their religiousness was a frequent topic during interviews, coffee sessions, and hallway conversations, usually with a note of concern. Several teachers commented on increasing competition between students over "who is the best Muslim".

Mrs. Schmidt: Currently the situation of the students is that they have to react when someone insults their religion. They can't tolerate it. The students look amongst themselves - who is the better Muslim? - and they provoke each other.

The shift in the students' ideology and identities was seen as a cause for concern, especially in relation to increases in bullying and divisions along gender, ethnic, and religious lines.

At the same time, many students who turned to religion also showed positive changes. These students were noticeably less involved in illegal activities, such as (violent) crime and drugs. Islam has also increasingly gained a new status of 'cool' amongst youths 
(see also Gerlach, 2006; Herding, 2013) and, for example, encouraged a positive identity formation amongst German Muslim women (Mushaben, 2008). The ideological shift, therefore, was not only seen as alarming; some changes were welcomed. There were doubts, however, amongst some students and staff as to whether faith was the true motivation for these changes. Many felt the increase in the role of religion was more due to peer pressure and fashion, and therefore, they questioned the seriousness of students' ideological turn.

Mr. Sadik: Last year it was 10-15 students who put on headscarves because they were bullied. It's more fashion then faith. It's group dynamic - wear a headscarf and don't have a boyfriend. There really are not many who are really faithful here. There is one girl, and her family is very active at the mosque and she's really a believer, but the rest? It's fashion and pressure from others.

This emphasis on religion is a rather recent phenomenon. Teachers, as well as older students, recall the shift occurring gradually since the early 2010 s, concurrent with three influential processes that impacted the political climate while the students were coming of age. The first was the rise of the Islamic State (IS) in the Middle East. While no student to whom we spoke supported IS - many saw IS as an embarrassment to Islam - tensions between religious and ethnic groups played out in the school arena. Students watched YouTube videos of slaughters and persecutions and brought these stories into the school environment, looking to situate and contrast themselves, their religious groups, and their ethnicities within the student body. In the diverse school environment, students felt pressure to position themselves for or against the violence, and for or against the perpetrators, victims, or both. The effects of these pressures were visible in the school arena:

Mr. Sadik: The [IS] crisis makes everything a lot more difficult. Never before have students taken religion as so central. "What religion are you?" I am this, I am that. Before, that was totally irrelevant. It was more "Oh, you're Muslim - OK!" Now it's are you Sunni, Shiite and so forth, and as a result there is a lot of bullying.

Social pressure and bullying based on religion and positioning amongst the students was frequent and pervasive, as was the quick turn to violence if insults felt too threatening to one's self, family, or group. While friendships frequently crossed religious and ethnic boundaries, being or not being a Muslim was often a decisive in- or out-group determinant. And while conflicts amongst students usually arose from everyday occurrences, once tensions came up, insults or threats often mounted along lines of religious dedication, practices, and followings, as well as ethnic differentiation. In addition, questions of what was haram (prohibited under Islamic law) and halal (allowed under Islamic law) were part of daily contemplations related to food, dress, and behaviors such as dating.

The second influential process that impacted the students in their religious positioning came from closer to home. They were often confronted with discrimination as they navigated the Berlin-Neukölln neighborhood and, especially, other neighborhoods. Berlin is the meeting point of what were once East and West Germany, and differences in how migrants are perceived and treated in the two areas are readily apparent despite their reunification in 1990. What was previously West Germany, including parts of Berlin, holds 93.6\% of the migrant population, while the former Eastern states hold less than 4\% (Statistisches Bundesamt, 2017). Housing, employment, and everyday discrimination contribute to this longstanding division (SVR, 2018). Navigating outside Berlin-Neukölln, and increasingly also inside 'foreigner areas', is met with experiences of perceived and actual discrimination (Tize \& Reis, 2019).

A third process - or rather, structural shift - in the students' lives that is believed to have a significant impact on young people is the transition out of school and into post-secondary education or employment. While many of the students were treated as examples of familial success, often being the first to receive graduation certificates, they did not receive the same reception in the post-completion educational or professional worlds. While their grades may have been average or even high at their school, compared to the highest-tier schools, their grades were often much lower. ${ }^{9}$ Additionally, the stigmatized 'Neukölln' certification stamp often caused a devaluation of graduation certificates (Eksner, 2013). As a result, trouble with receiving vocational or post-secondary education or employment, especially for those leaving with lowertier (only grade 9 or 10) certificates, was identified by teachers as the biggest risk factor for rejecting German society and intensifying one's alignment with ethnic and religious identities.

After Charlie Hebdo, the school environment was not seen as being a risk factor for students' distancing themselves from their peers or turning against German society. Rather, the staff feared what would happen after they left school.

Mr. Herbert: What is decisive, especially amongst the upper classmen, because (...) I got into confrontations with them about Charlie Hebdo, is how well they are integrated after their secondary school completion. 
Do they get entry into a university? If yes, in time, I think then it'll all be fine. If they don't get further and fail, despite getting quite far [by receiving a grade 13 graduation certificate], and then get stuck, that is what I believe is the decisive tipping point.

Experiences of discrimination and marginalization were often apparent during schooling. However, many students' stories were based on the negative experiences of older siblings, or cousins who had finished school and faced issues with discrimination as they struggled to find work or educational positions outside Neukölln. Additionally, many students had few or no German friends, or contacts outside of the diasporic environments in which they were raised.

Looking at the school itself, to difficulties encountered during the transition to post-secondary education or employment, to the rise of IS, and to anti-Islam movements in Germany and elsewhere in Europe, a fuller picture of factors influencing students' reactions to the Charlie Hebdo attack emerges. Increasing peer pressure to overtly perform specific aspects of Muslim identity is being felt by students of all ages. Prior to Charlie Hebdo, contemplations of and insecurities around being a foreigner and a Muslim were already part of students' daily lives. Students were using foreigner, ethnic, and Muslim identities as labels to explain why they felt they could not be or become German. In particular, Muslim students and those with darker complexions - dark hair, skin, and eyes - claimed these identities with a sense of pride (Tize \& Reis, 2019; Çelik, 2015). While identities often shifted depending on environment and situation, when confronted with non-Muslims, being a Muslim often trumped students' other foreigner or ethnic identities. As students learned to situate themselves between ethnic and religious differences in a multicultural environment, contemplations of who they were and what kind of Muslim they were, both in private and in public, invited increased social pressure, especially from certain (self-proclaimed) authoritative students.

\section{Discussion}

Prior events, such as the 9/11 attacks in 2001 and the 2005 Danish cartoon controversy, have significantly influenced the representations and positions of Muslims in the West. The 9/11 attacks united Western nations against the perceived growing threat of Islamic terrorism, and inspired the "global war on terror"; while the Danish cartoons, which insulted the prophet Mohammed, "created a platform that Muslim communities [used] to counter Western hegemonies" (Kublitz, 2010, p.108). Scholars have discussed how "post-9/11 youths", a "post-9/11 environment", and increasingly negative (mis)representations of Muslims in the Western world since 9/11 have affected both how Muslims identify themselves and how they are identified by others (White Tindongan, 2011; Ahmed \& Matthes, 2017). Charlie Hebdo, rather than representing a historical rupture, constitutes an intensification of these extant processes (Korsbrekke, 2015). We suggest that the students' reactions - just as the attack on Charlie Hebdo - need to be understood against a longstanding historical backdrop of discrimination, marginalization, and structural violence towards those who are considered non-European (cf., Bertelsen and Zagato, 2015).

The reactions of the students in Neukölln show how the effect of terrorist attacks can transcend national boundaries - in this case, affecting how Muslim students feel and position themselves in Germany. Both direct exposure to terrorist attacks and indirect exposure through the media can have detrimental consequences for well-being (Metcalfe, Powdthavee and Dolan, 2011). Supporting the findings of the effects on Muslims after 9/11 (Abu-Ras \& Abu Bader, 2008; Seirmarco et al., 2012), research by Liepyte and McAloney-Kocaman (2015) suggests that the attacks on Charlie Hebdo had international effects and resulted in higher perception of discrimination as well as religious coping and engagement amongst Muslim women in England. The Charlie Hebdo events brought to the forefront an intensification of longstanding divisions, and for Muslims, feelings of marginalization, discrimination, and an inability to have a voice or shape a true sense of belonging in Europe.

The attack raised the consciousness of the students at the Neukölln secondary school and their experience as 'Muslims' in Germany - amidst rising polarization and xenophobia. What is at stake for these young people is informed by their everyday experiences. Students were concerned with how they were perceived by peers, teachers, and family members, and how their positioning affected their own safety in an environment prone to bullying and violence. These different sets of pressures facing students align with different arguments in previous research. Firstly, the students' aims of being against the violence often stood in contradiction to their own life experiences. Paulle (2014) has shown that the primacy of conflicts lies not in race, religion, or ethnicity, but rather in the everyday, the momentto-moment happenings in school that drive students' reactions and feelings. In his ethnography of two inner-city neighborhood schools in the Netherlands and in the United States, Paulle noted that students' acting or becoming "hard" was a response to chronic stress. What he considered to be crazy, stupid, or wild actions in fact felt effective to students and achieved their desired short-term effects. In some ways, 
sympathizing with terrorists or making big claims is a way of satisfying students' desires to shock teachers and peers, and of temporarily gaining attention and respect from peers. Their reactions can be analyzed as attempts to deal with external stressors resulting from their foreign, ethnic, and/or Muslim identities that they repeatedly encountered throughout their everyday experiences inside and outside of school. Bullying and quick-temper reactions to confrontations habituated and situated attempts to shield themselves in hostile settings (Paulle, 2014).

Positioning our findings within the literature on the increase in religiously-oriented ideological attachments suggests that one exercise caution when analyzing students' reactions to terrorist attacks. For example, ethnographic research by Julia Gerlach (2006) and Maruta Herding (2013) show the double-sided perspective of how young Muslims in Germany are embracing an increasing status of Islam as 'cool'. On the one hand, many Muslims have embraced a young and fashionable Islam linked to consumer culture with a strong commitment to society. Islamic youth culture must be seen as a vehicle for integration, because the state has not offered alternative routes (Herding, 2013). On the other hand, a strong conservatism and anti-West opinions have taken root, which have left an open door to extremist views. While the processes influencing a negative perception of society differ based on the context, often, experiences of rejection and discrimination fuel an increase in strong beliefs (Herding, 2013; Liepyte \& McAloney-Kocaman, 2015). Especially for young people, who are engaged in a critical period of identity construction and are situating themselves in group dynamics, exposure to discrimination and personal uncertainty can have detrimental effects on the development of forms of belonging and feelings of exclusion - creating a rise in ethnic identity formation (Rumbaut, 2005). Doosje and colleagues (2013) have argued that personal uncertainty makes young people more susceptible to extremist ideas and groups. For young people who are contemplating their identities, such as the students in this study confronted with questions like "What kind of Muslim am I?" and "Am I part of this?", extreme ideas can provide guidance and clear, straightforward answers, thereby reducing uncertainty and helplessness.

Such complex and at times contradictory findings suggest the need for a thorough investigation of young people's perspectives, thereby preventing the preemptive placement of young people within a risk category. Therefore, we suggest going beyond one single expression of a viewpoint in order to prevent caricaturing of young peoples' voices. Namely, exploring how students positioned themselves in relation to the Charlie Hebdo attack revealed the importance of analyzing their narratives as multilayered. In his work analyzing Greek-Cypriot children's constructions of national identities, Spyrou (2001) found that children drew on different narratives within and outside the school. Within the school, students provided the 'correct answer', but outside the school, they drew on alternative discourses, which at times contradicted what they said in school. The data in this paper revealed that, even within a school environment, students' answers shifted depending on the situation, and even developed throughout the interview. As such, taking the initial context-driven answers from a single setting could lead to a misrepresentation of respondents' perspectives. Our focus on Charlie Hebdo allowed for a more thorough investigation of ethnographic realities and of what is truly at stake for students when responding to such an event.

Our findings point to factors that influence students' reactions to events like Charlie Hebdo, and provide a foundation for understanding the processes affecting their reactions. We agree with Herding (2013) in a lack of transnational and limited national consciousness of similar scenes of Islamic youth culture, and we therefore emphasize the significance of understanding the local context and processes that influence young people as an important element of prevention and intervention work. In addition to understanding the context, periods of uncertainty, such as transitions between schools, or from school to work or university, are an important time to support and guide students to continually encourage a healthy relationship to society. Particularly, feelings of uncertainty and insignificance have shown to increase the appeal of extremist groups (Webber et al., 2018). Our findings suggest that the provision of support to religious minority groups can provide necessary guidance in grappling with global events and the (potential) social shifts (Liepyte \& McAloney-Kocaman, 2015). This kind of support is important not just in relation to the responses of the religiously motivated attacks themselves, but also in relation to the effects of increased discrimination from the wider public.

This study has shown the struggles and turmoil that the teachers have faced while confronted with the aftereffects of the events at Charlie Hebdo, with little knowledge and training. Because schools play an increasing role in providing a space for students to contemplate identities and forms of belonging (see Tize \& Reis, 2019), it is crucial for teachers and social workers to understand what is at stake for students during critical times of social and political upheaval. Through everyday contact, teachers and social workers are in an ideal position to help with the early detection of students who have feelings of insignificance (Webber et al., 2018) or who display and enact oppositional identities - which comprise a rejection of the dominant culture through displays of 'coolness', ethnic pride, and 
defiance of authorities (Celik, 2015). Therefore, in addition to working with identified students, the role of social and clinical psychologists may reside in training the school staff in mental health literacy, that is, in how to assess students who are at risk and how to refer them for appropriate psychosocial or other support. In this process, both teachers and social workers may also benefit from learning to assess and integrate inclusionary discourses in the classroom.

Our research adds to a growing body of literature about understanding young people amidst longstanding (and indeed, rising) xenophobia and polarization. However, much still needs to be understood to foster a harmonious Zusammenleben (living together). To aid in this understanding, we have three suggestions for further research. First, a systemic approach that focuses not just on the students, but also on their teachers, has the potential to provide clear insight into the potential effects of polarizing discourses between students and staff. Second, our focus was on the students who spoke out after the attacks, rather than those who chose to stay silent. A focus on those who chose to stay silent may reveal an alternative to the reactions we have described. Third, we have suggested that the risk for students' oppositional, or 'reactive' ethnic identity formation (Rumbaut, 2008) may not be the school environment itself, but rather those related to the transition out of school. Further research on this transition can explore the experiences of how further education or entering the workforce shape experiences and processes that influence ethnic identity formation and forms of (non-) belonging.

To conclude, we want to emphasize that our findings highlight the importance of considering all factors that drive students' responses to terrorist attacks. Young people's insecurity in their identities and sense of belonging makes them easily influenced by social pressures. In addition to teaching required curricula, schools are expected to nurture the pride and history of marginalized communities, and address students' counter-narratives and their (at times) discriminating and marginalizing experiences in society (Bhui, Hicks, Lashley, \& Jones, 2012). In addition, schools are an important place for young people to grapple with international events and to contemplate their socio-political identities in relation to these events. Schools are therefore a vital site for researching the processes that influence the expression of extreme viewpoints - and simultaneously a place for implementing appropriate support and interventions.

\section{Conclusion}

By looking at Charlie Hebdo as a critical event embedded within multidimensional processes, we can see the foundations of students' reactions to the attacks as complex presentations of confusion and inconsistencies, driven by simmering discontent with long-standing structural forces. Therefore, the students' reactions to Charlie Hebdo cannot be understood without considering the broader socio-political context of Muslims in Germany and Europe. As we have shown, the attack on Charlie Hebdo has brought to the forefront many processes that would otherwise remain more hidden, such as discrimination, marginalization, and feelings of not being heard. The attacks furthermore forced students to contemplate what it means to be a 'good' Muslim. Following the attacks, the pressures facing students came out of their immediate environment. Students were forced to situate themselves for or against the attackers or chose the position to regard Charlie Hebdo as 'faked'. Positioning came out of how the student was situated in relation to peers, teachers, and family members, and how their positioning affected their own safety in an environment prone to bullying and violence. Additionally, increasing tensions in social relations in their everyday lives and in the broader society affected students' reactions. For teachers, students' responses to Charlie Hebdo evoked panic and fear, and pressure to intervene when students' expressions of religious and ethnic identity were perceived as too 'extreme'. These findings emphasize the importance of context and the ethnographic method to accurately interpret the responses of students to terrorist attacks. By considering the context and the social situation students are immersed in, we can avoid misinterpretations or caricatures of students, whose responses are fueled by complex processes from different levels of society.

\section{Acknowledgements}

We especially want to thank the students, their families, the school staff, and affiliated organizations for welcoming Carola and her inquisitions into the everyday happenings in the classroom, the homes, and the spaces in between. We furthermore want to thank Ashley Witcher providing support and feedback on earlier drafts. Last and definitely not least, we are extremely grateful for the insightful feedback from the reviewers of Transcultural Psychiatry.

\section{Declaration of Conflicting Interests}

The author(s) declared no potential conflicts of interest with respect to the research, authorship, and/or publication of this article.

\section{Funding}

The author(s) received no financial support for the research, authorship, and/or publication of this article.

\section{Notes}

1. This research was conducted to investigate how students perceive and navigate their futures and reproduce or resist intergenerational reiteration of inequity. 
2. The ethnic and religious differences at the school are impossible to accurately represent. Any attempts to estimate belonging to an ethnic or religious group may not truly portray the diversity of the student body, because some students may not have openly revealed their religious affiliations to the staff, the first author, or their peers, because of issues of bullying and discrimination. However, we can broadly say that, amongst those following Islam, the majority are Sunni, and a significant lower number are Shiite. Also worth mentioning are a number of various ethnic-religious groups, including Kurds, Lebanese-Kurds (Mhallami), and a very small number of Yizidi, which also attend the school.

3. While the 'young' participants ranged between 9 and 27 years of age, and the majority were aged 11 to 15 and in grades 6 to 8 respectively.

4. Tize was born in Germany and moved to Canada as a child. She grew up bilingually, speaking both German and English.

5. In line with Gluckman's (1940) approach to the critical event, ethnographers should carefully reflect on their own positioning in relation to situating the event. It is worth mentioning again that the attack on Charlie Hebdo as a critical event allowed the previously invisible to become visible and analyzable - mostly because it was sudden and the repercussions were unpredictable. Therefore, the interviews were quite spontaneous, and at times even chaotic, because the interviewer had to respond to surprising (and at times shocking) answers from students that she had known for nearly two years. However, it was precisely this 'chaos' after the event that allowed the underlying issues to surface and become analyzable. The first author was undoubtedly emotionally affected and, at times, struggled with the students' answers and providing (counter-) perspectives without losing or triggering the students during the interviews. In order to balance the intense period of data collection and periods of reflection in the weeks after Charlie Hebdo, the first author did receive intensive feedback and support from her supervisors. We view the data to fully represent the situation, and the openness of the interviews most likely allowed the students to present their ideas, experiences, and interpretations freely.

6. See Gestring (2011) for an overview of circumstances in Germany and fears of parallel societies. Schönwälder and Sohn (2009) showed that these fears were unfounded migrant neighborhoods were, and still are, incredibly diverse, with little social cohesion between the diverse groups.

7. These media representations are not restricted to Germany. See Ahmed and Matthes (2017) for a full meta- analysis of media representations of Muslims and Islam from 2000 to 2005.

8. Conspiracy theories can be analyzed as part of broader social structures and contexts, and "can be viewed as a form of populist protest against structural inequities and the legitimacy and authority of the powerful elite in politics and society" (Jamil \& Rousseau, 2011, p. 247). As a result, marginalized groups more frequently tend to rely on them for explaining adverse political events.
9. Worth noting is Germany's 2001 "PISA shock". The PISA study results revealed Germany has the least social mobility of any OECD country (OECD, 2001), and despite its best efforts, it has struggled to alter this (Quenzel \& Hurrelmann, 2010). The results thereby confirmed that in Germany, poverty and low levels of education are intergenerationally transmitted in the lower social classes, especially amongst children of migrants. Young people from migrant backgrounds were highly overrepresented in the lowest tier of the educational system, and thus experienced limited future possibilities (Ramirez-Rodriguez \& Dohmen, 2010). In response, Berlin implemented major school reforms, starting in 2005. These created comprehensive secondary schools (grades 7 to 13 ) that allowed all three educational tiers to be offered within the same building. Other efforts introduced whole-day schooling and increased hiring of multicultural staff to better serve students from migrant families.

\section{References}

Abu-Ras, W., \& Abu-Bader, S. H. (2008). The impact of the September 11, 2001 attacks on the well-being of Arab Americans in New York City. Journal of Muslim Mental Health, 3(2): 217-239.

Ahmed, S., \& Matthes, J. (2017). Media representation of Muslims and Islam from 2000 to 2015: A meta-analysis. International Communication Gazette, 79(3): 219-244.

Bertelsen, B. E., \& Zagato, A. (2015). Introduction: The event of Charlie Hebdo - imaginaries of freedom and control. In: A. Zagato (Ed.) The event of Charlie Hebdo: Imaginaries of freedom and control (Critical I) (pp. 1-11). Oxford: Berghahn Books.

Bhui, K. S., Hicks, M. H., Lashley, M., \& Jones, E. (2012). A public health approach to understanding and preventing violent radicalization. BMC Medicine, 10(16): 1-8.

Bock, J. J., \& Macdonald, S. (2019). Introduction. In: J. J. Bock, \& S. Macdonald (Eds.), Refugees welcome? Making, experiencing and managing difference in a changing Germany (pp. 1-38). Oxford: Berghahn Books.

Çelik, Ç. (2015). "Having a German passport will not make me German": Reactive ethnicity and oppositional identity among disadvantaged male Turkish second-generation youth in Germany. Ethnic and Racial Studies, 38(9): 1646-1662.

Der Spiegel (1973, July 30). "Die Türken Kommen - rette sich, wer kann". Der Spiegel, pp. 23-34. Retrieved November 7, 2018 from http://www.spiegel.de/spiegel/ print/d-41955159.html

Doosje, B., Loseman, A., \& van den Bos, K. (2013). Determinants of radicalization of Islamic youth in the Netherlands: Personal uncertainty, perceived injustice, and perceived group threat. Journal of Social Issues, 69(3): 586-604.

Ehrkamp, P. (2008). Risking publicity: Masculinities and the racialization of public neighborhood space. Social and Cultural Geography, 9(2): 117-133.

Eksner, H. J. (2013). Revisiting the "ghetto" in the New Berlin Republic: Immigrant youths, territorial 
stigmatisation and the devaluation of local educational capital, 1999-2010. Social Anthropology, 21, 336-355.

Ellerman, A. (2009). States against migrants: Deportation in Germany and the United States. Cambridge, UK: Cambridge University Press.

Fassin, D. (2015). In the name of the Republic: Untimely mediations on the aftermath of the Charlie Hebdo attack. Anthropology of Work Review, 31(2): 3-7.

Foroutan, N. (2019). The post migrant paradigm. In: J. J. Bock, \& S. McDonald (Eds.), Refugees welcome? Difference and diversity in a changing Germany (pp. 142-168). Oxford, UK: Berghahn Books.

Gerlach, J. (2006). Zwischen Pop und Dschihad: Muslimische Jugendliche in Deutschland. Berlin: C. H. Links Verlag.

Gluckman, M. (1940). Analysis of a social situation in modern Zululand (Rhodes- Livingstone Papers No. 28). Manchester.

Gestring, N. (2011). Parallelgesellschaft, Ghettorisierung und Segregation - Muslime in Deutschen Städten. In Politik und Islam (pp. 168-190). Wiesbaden, Germany: VS Verlag.

Golo, N. (2015). A case study of conspiracy theories about Charlie Hebdo terrorist attack. Eprint arXiv, October 2, 114. Retrieved from http://arxiv.org/abs/1510.00037

Herding, M. (2013). Inventing the Muslim cool: Islamic youth culture in Western Europe. Bielefeld: transcript Verlag.

Jamil, U., \& Rousseau, C. (2011). Challenging the "official" story of 9/11: Community narratives and conspiracy theories. Ethnicities, 11(2): 245-261.

Kapferer, B. (2010). Introduction: In the event - toward an anthropology of generic moments. Social Analysis, 54(3): $1-27$.

Korsbrekke, M. H. (2015). Where were you, Charlie? Contesting voices of political activism in the wake of a tragedy. In: A. Zagato (Ed.) The event of Charlie Hebdo: Imaginaries of freedom and control (Critical I pp. 56-66). Oxford, UK: Berghahn Books.

Kublitz, A. (2010). The cartoon controversy: Creating Muslims in a Danish setting. Social Analysis, 54(3): 107-125.

Lichtfield, J. (2015, January 9). Charlie Hebdo: After France's 9/11, this land will never be the same again. Independent. United Kingdom. Retrieved November 1, 2018 from https://www.independent.co.uk/voices/comment/charlie-hebdo-after-france-s-911-this-land-willnever-be-the-same-again-9969165.html

Liepyte, S., \& McAloney-Kocaman, K. (2015). Discrimination and religiosity among Muslim women in the UK before and after the Charlie Hebdo attacks. Mental Health, Religion and Culture, 18(9): 789-794.

Metcalfe, R., Powdthavee, N., \& Dolan, P. (2017). Destruction and distress: Using a quasi experiment to show the effect of the September 11 attacks on mental well-being in the United Kingdom. The Economic Journal, 121(550): 81-104.

Mushaben, J. M. (2008). Gender, hiphop and pop-Islam: The urban identities of Muslim youth in Germany. Citizenship Studies, 12(5): 507-526.

OECD. (2001). Lernen für das Leben. Erste Ergebnisse der Internationalen Schulleistungsstudie PISA 2000. Retrieved from https://www.oecd-ilibrary.org/docserver/978926459 5903-de.pdf?expires $=1580969955 \& i d=i d \& a c c n a m e=$ guest\&checksum $=9874 \mathrm{E} 652 \mathrm{CDF} 70 \mathrm{C13A} 4 \mathrm{~EB} 9776963 \mathrm{~B}$ 86A5

Paulle, B. (2014). Coming hard: The primacy of embodied stress responses in high poverty schools. European Journal of Sociology, 55(1): 83-106.

Pratt-Ewing, K. (2008). Stolen honor: Stigmatizing Muslim men in Berlin. Stanford, CA: Stanford University Press.

Quenzel, G., \& Hurrelmann, K. (2010). Bildungsverlieherer: Neue soziale Ungleichheiten in der Wissensgesellschaft. In: G. Quenzel, \& K. Hurrelmann (Eds.), Bildungsverliehrer: Neue Ungleichheiten (pp. 11-33). Wiesbaden, Germany: VS Verlag.

Ramirez-Rodriguez, R., \& Dohmen, D. (2010). Ethnisierung von geringer Bildung. In: G. Quenzel, \& K. Hurrelmann (Eds.), Bildungsverliehrer: Neue Ungleichheiten (pp. 289-311). Wiesbaden, Germany: VS Verlag.

Rumbaut, R. G. (2005). Sites of belonging: Acculturation, discrimination, and ethnic identity among children of immigrants. In: T.S. Weiner (Ed.) Discovering Successful Pathways in Children's Development: Mixed Methods in the Study of Childhood and Family Life (pp. 111-164). Chicago: University of Chicago Press.

Rumbaut, R. G. (2008). Reaping what you sow: Immigration, youth, and reactive ethnicity. Applied Developmental Science, 12(2): 108-111.

Seirmarco, G., Neria, Y., Insel, B., Kiper, D., Doruk, A., Gross, R., \& Litz, B. (2012). Religiosity and mental health: Changes in religious beliefs, complicated grief, posttraumatic stress disorder, and major depression following the September 11, 2001 attacks. Psychology of Religion and Spirituality, 4(1): 10-18.

Schönwalder, K., \& Sohn, J. (2009). Immigrant settlement structures in Germany: General patterns and urban levels of concentration of major groups. Urban Studies, 46(7): 1439-1460.

Spielhaus, R. (2013). Vom Migranten zum Muslim und wieder zurück Die Vermengung von Integrations- und Islamthemen in Medien, Politik und Forschung. In D. Halm \& H. Meyer (Eds.), Islam und die deutsche Gesellschaf (pp. 169-194). Springer VS, Wiesbaden.

Spielhaus, R. (2006). Religion and identity: How Germany's foreigners have become Muslims. Internationale Politik Transatlantic Edition, 2(8): 17-23.

Spyrou, S. (2001). Being one and more than one: Greek Cypriot children and ethnic identity in the flow of everyday life. disClosure: A Journal of Social Theory, 10, 73-94.

Statistisches Bundesamt. (2017). Ergebenisse des Mikrozensus Bevölkerung und Erwerbstätigkeit: Bevölkerung mit Migrationshintergrund (Vol. Fachserie). Retrieved from https://www.destatis.de/DE/Publikationen/Thematisch/ Bevoelkerung/MigrationIntegration/Migrationshintergrund2010220167004.pdf?_blob=publicationFile\#page $=43$

Stichs, A. (2016). Wie viele Muslime leben in Deutschland? Eine Hochrechnung über die Anzahl der Muslime in Deutschland zum Stand 31 Dezember 2015 (No. 71). Deutsche Islam Konferenz. Retrieved from https://www. bamf.de/SharedDocs/Anlagen/DE/Forschung/ WorkingPapers/wp71-zahl-muslime-deutschland.pdf? blob $=$ publicationFile \&v $=12$ 
SVR. (2018). “Wo kommen Sie eigentlich ursprünglich her?” Diskriminierungserfahrungen und phänotypische Differenz in Deutschland. Retrieved from https://www.svr-migration.de/wp-content/uploads/2018/01/SVR-FB Diskriminierungserfahrungen.pdf

Tize, C., \& Reis, R. (2019). "Neukölln is where I live, it's not where I'm from": Children of migrants navigating belonging in a rapidly changing urban space in Berlin. In: J. J. Bock, \& S. McDonald (Eds.), Refugees welcome? Difference and diversity in a changing Germany (pp. 121-141). Oxford, UK: Berghahn Books.

Webber, D., Babush, M., Vazeou-nieuwenhuis, A., Bélanger, J. J., Moyano, M., Trujillo, H. M.,... Gelfand, M. J. (2018). The road to extremism $\square$ : Field and experimental evidence that significance loss-induced need for closure fosters radicalization. Journal of Personal and Social Psychology, 114(2): 270-285.

White Tindongan, C. (2011). Negotiating Muslim youth identity in a post-9/11 world. The High School Journal, 95(1): $72-87$.

Wiegel, M. (2015). Charlie Hebdo: Hass in Frankreichs Klassenzimmern. Retrieved January 16, 2015, from http://www.faz.net/aktuell/nach-pariser-anschlaegenherrscht-hass-in-frankreichs- schulen-13372074.html.

Carola Tize (MA) is a PhD candidate at the Amsterdam Institute for Social Science Research (AISSR), University of Amsterdam. Her PhD research focuses on the processes affecting the intergenerational transmission of vulnerabilities amongst children of migrants in Berlin, and the role of youth agency in either reiterating or resisting the trends through the generations. Her Masters in medical anthropology and her particular interest in (school) psychology have contributed to her focus on young people and experiences of discrimination and marginalization.

Lidewyde Berckmoes, MA, PhD, is Assistant Professor of Regional Conflict in Contemporary Africa at the African Studies Centre Leiden and is affiliated with the University of Amsterdam. Her work focuses on how conflict-affected children and youth navigate their environments. In her current work, she explores intergenerational transmission of conflict and its effects on cycles of violencein various African contexts.

Joop de Jong, MD, PhD, is Emeritus Professor of Cultural Psychiatry and Global Mental Health at UMC Amsterdam, Adjunct Professor of Psychiatry at Boston University School of Medicine, and Emeritus Visiting Professor of Psychology at Rhodes University, South Africa. He was the founder and director of the Transcultural Psychosocial Organization (TPO), which provided mental health and psychosocial services in more than 30 countries in Africa, Asia, and Europe. Joop de Jong worked part-time as a psychotherapist and psychiatrist with immigrants and refugees in the Netherlands. He has been integrating insights from public mental health, psychotherapy, psychiatry, anthropology, and epidemiology into community interventions in a variety of cultures, on which he coauthored over 300 papers, chapters, and books.

Ria Reis, MA, PhD, is Professor of Medical Anthropology at the Department of Public Health and Primary Care, Leiden University Medical Centre (LUMC), Associate Professor at the Department of Anthropology, University of Amsterdam, and Academic Staff member at the Amsterdam Institute of Global Health and Development (AIGHD). She also is Honorary Professor at the Children's Institute, University of Cape Town. Core themes in her research are the intergenerational transmission of vulnerabilities in contexts of inequality and (post)conflict, and health perceptions, strategies, and resilience of young people. She has a particular interest in youth mental health and cultural idioms of distress as expressions of communal social suffering in regions affected by epidemics, disasters, conflicts, and violence. 